\title{
KEPADATAN DAN DISTRIBUSI LARVAE DIPTERA PADA PHYTOTELMATA DI DAERAH ENDEMIS DEMAM BERDARAH DENGUE DI SUMATERA BARAT
}

\author{
Emantis Rosa \\ Jurusan Biologi FMIPA Universitas Lampung \\ e-mail: iccaindah@ymail.com \\ Jurusan Biologi FMIPA Universitas Lampung \\ Jl. Soemantri Brojonegoro No.1, Bandar Lampung, Lampung, Indonesia, 35145
}

\begin{abstract}
Abstrak
Penelitian tentang komposisi dan distribusi larva Diptera pada Phytotelmata telah dilakukan di tiga lokasi pemukiman daerah endemis demem berdarah dengue yang bertujuan untuk mengetahui komposisi dan distribusi larva Diptera pada phytotelmata. Hasil penelitian didapatkan komposisi larva Diptera pada phytotelmata terdiri dari Ae. aegypti, Ae. albopictus, Cx.tritaeniorhynchus, Ar.subalbatus, Chironomus sp. Tipula sp., Psychoda sp. Ke tujuh larva Diptera terdistribusi pada ke empat jenis phytotelmata dengan nilai ragam Komponen Utama1. $(98,03 \%)$ dan nilai ragam Komponen Utama 2. (1,55\%) dan total keragaman sebesar $(99,58 \%)$.dan sebagai larva penciri pada ke empat jenis phytotelmata adalah larva Ae.albopictus.
\end{abstract}

\section{PENDAHULUAN}

Phytotelmata adalah tumbuhan yang menampung genangan air yang berada di dalam atau di bagian tumbuhan, yang digunakan oleh berbagai organisme sebagai tempat hidup termasuk serangga (Kitching, 1971; Kitching, 2000, 2001; Marguire, 1971, Fish (1983). Phytotelmata dapat ditemukan dimana saja dengan jenis yang berbeda-beda, terutama di tempattempat yang lembab seperti di daerah tropis (Greeney, 2001). Fish (1983), melaporkan diperkirakan ada 29 famili, 60 genus, dan 6 Ordo serta 1.500 jenis tumbuhan tergolong phytotelmata. Phytotelmata mempunyai berbagai macam tipe antara lain, pitcher plant, lubang pohon, kelopak daun, kelopak bunga, lubang buah (Kitching, 1971).

Berbagai penelitian tentang phytotelmata telah dilakukan oleh beberapa peneliti antara lain: Distribusi larva nyamuk pada tunggul bambu (Sunahara and Mogi, 1997); Phytotelmata dan nyamuk vektor demam kuning di Afrika (Pajot,1983); Pola ekologi serangga air pada tanaman pitcher (Barrera et el., 1989); Pengaruh beberapa faktor physikokimia terhadap perkembangan dan kemelimpahan nyamuk pada phytotelmata (Delonyx regia) (Adebote at al., 2008); Komposisi serangga pada lubang pohon, tunggul bambu dan bunga Zingiberaceae di Padang (Abbas et al. 2003). Tipe dan jenis phytotelmata di pemukinan di kota Padang (Rosa, at. al. 2012). Tetapi bagaimana kepadatan larva Diptera pada phytotelmata yang terdapat di pemukiman di Sumatera Barat, sampai sejauh ini belum ada informasinya. Penelitian ini bertujuan untuk mengetahui kepadatan dan distribusi larva Diptera pada phytotelmata di pemukiman di Sumatera Barat.

\section{BAHAN dan METODE}

Penelitian dimulai bulan Januari sampai Desember 2012, di tiga lokasi di Sumatera Barat yaitu Kota Padang, yang terletak pada $00^{\circ} 53^{\prime}$ $666^{\prime \prime}-00^{\circ} 53^{\prime} 786^{\prime \prime}$ LS dan 100² $21^{\prime} 999^{\prime \prime}-100^{\circ} 2^{\prime}$ 968" BT, elevasi $18 \mathrm{~m}$ diatas permukaan laut (dpl.). Kota Bukittinggi lokasi terletak pada( $00^{0} 18^{\prime} 899^{\prime \prime}-00^{0} 17^{\prime} 898^{\prime \prime}$ LS dan $100^{\circ} 23^{\prime} 61^{\prime \prime}-100^{\circ}$ 22'62" BT), elevasi $939 \mathrm{~m}$ dpl. Kota Payakumbuh terletak pada $\left(00^{\circ} 12^{\prime} 935^{\prime \prime}-00^{0} 12935^{\prime \prime}\right.$ LS dan 100037'901"-100'37'899" BT), elevasi 534 $\mathrm{m}$ dpl. Curah hujan berkisar $(20-80 \mathrm{~mm})$, suhu berkisar $\left(21,61^{0}-28,53^{\circ}\right)$ dan kelembaban ratarata berkisar (50,5\%-89,92\%) (Stasium Klimatologi Sumatera Barat, dan MBKG Bandara Minang Kabau, 2012).

Pemilihan phytotelmata guna pengambilan sampel larva mengacu kriteria Kitching (1971). Teknik pengambilan sampel mengikuti cara Derraik (2005) yang dilakukan dengan menggunakan pipet/sedotan, sampel disortir, sehingga terpisah sampah kasar dan kotoran lainnya. Air yang sudah terpisah dari kotoran dan sampah dipisahkan larvanya. Larva yang sudah terpisah diidentifikasi mengacu Phua Sai Gek, et al., (2008, 2010).

Identifikasi larva Diptera dilakukan di Laboratorium Riset, Taksonomi Hewan, Jurusan Biologi FMIPA Universitas Andalas. Larva Diptera yang ditemukan dihitung jumlahnya, larva yang sudah mati, dimasukkan ke dalam botol yang berisi alkohol $70 \%$ untuk di identifikasi, sedang 
masih hidup dipelihara sampai dewasa untuk memastikan hasil identifikasi. Pengambilan sampel larva Diptera dilakukan setiap dua minggu sekali, selama satu tahun meliputi jenis dan jumlah individu larva.

Analisis data untuk mengetahui kepadatan dan Frekuensi kehadiran (FK) larva Diptera mengikuti formula Michael (1984). Kepadatan diperoleh dengan membagi jumlah jenis individu larva dengan jumlah volume air pada phytotelmata $(\mathrm{ml})$. Untuk mengetahui distribusi larva Diptera pada phytotelmata, dianalisis dengan Multivariate Analisis PCA (Principal Camponent Analysis), menggunakan program komputasi PAST (Hammer, 2012)

\section{HASIL dan PEMBAHASAN}

\section{Kepadatan larva Diptera}

Komposisi larva Diptera pada phytotelmata dicantumkan pada Tabel 1. Jenis larva yanag ditemukan terdiri dari empat famili tujuh jenis. Ke tujuh jenis larva tersebut adalah Aedes aegypti, Aedes. albopictus, Culex tritaeniorhynchus, Amigeres subalbatus, Chironomus sp., Tipula sp., dan Psychoda sp. Kisaran kepadatan larva Diptera pada di pandan berkisar antara $0-0,1373$ individu/ml, di talas berkisar antara 0,013-0,5636 individu/ml, bambu antara 0,0029-0,3633 individu/ml dan pada nanas berkisar antara 0-0,5794 individu/ml. Dengan FK berkisar antara 75-100 \%. Kepadatan tertinggi ditemukan pada larva Ae. albopictus 2,1103 individu/ml dengan FK $100 \%$, diikuti $C x$. tritaeniorhynchus 0,5554 individu/ml,(FK100\%), Tipula sp.0,944 individu/ml ( FK 100\%)

\section{Distribusi larva Diptera pada phytotelmata}

Distribusi larva Diptera pada phytotelmata dari analisis PCA ditunjukkan pada (Gambar 2.) Dari gambar terlihat ke tujuh larva Diptera terdistribusi pada ke empat jenis phytotelmata dengan nilai ragam Komponen Utama1. $(98,03 \%)$ dan nilai ragam Komponen Utama 2. $(1,55 \%)$ dan total keragaman sebesar $(99,58 \%)$. Hasil ini mengindikasikan bahwa komposisi kepadatan larva Diptera pada ke empat jenis phytotelmata memperlihatkan pengelompokan komposisi yang sama. Dari Gambar 2. juga terlihat bahwa komposisi larva Diptera pada ke empat jenis phytotelmata sangat ditentukan oleh larva Ae. albopictus yang ditunjukkan oleh posisi larva ini yang menjauhi sumbu Komponen Utama 1 dan sumbu Komponen Utama 2.

Tabel 1. Kepadatan Larva Diptera pada phytotelmata

\begin{tabular}{|c|c|c|c|c|c|c|c|}
\hline \multirow[t]{2}{*}{ Jenis } & \multicolumn{4}{|c|}{ Kepadatan (ind./ml) } & \multirow[t]{2}{*}{ Kisaran } & \multirow[t]{2}{*}{ Total } & \multirow[t]{2}{*}{ FK (\%) } \\
\hline & Pandan & Talas & Bambu & Nanas & & & \\
\hline \multicolumn{8}{|l|}{ I.Chironomidae } \\
\hline 1. Chironomus sp. & 0,0871 & 0,063 & 0,0175 & 0,1193 & $0,0175-1193$ & 0,2869 & 100 \\
\hline \multicolumn{8}{|l|}{ II. Culicidae } \\
\hline 2. Ae.aegypti & 0,0289 & 0,0534 & 0,0218 & 0 & $0-0,0534$ & 0,1041 & 75 \\
\hline 3. Ae.albopictus & 0,604 & 0,5636 & 0,3633 & 0,5794 & $0,3633-0,604$ & 2,1103 & 100 \\
\hline 4. Ar. subalbatus & 0,0006 & 0,0534 & 0,0109 & 0,0262 & $0,0006-0,0534$ & 0,0911 & 100 \\
\hline 5.Cx.tritaenirhynchus & 0,1298 & 0,1774 & 0,0445 & 0,2037 & $0,1298-0,2037$ & 0,5554 & 100 \\
\hline \multicolumn{8}{|l|}{ III.Tipulidae } \\
\hline 6. Tipula sp. & 0,1373 & 0,0934 & 0,0453 & 0,218 & $0,0453-0,218$ & 0,494 & 100 \\
\hline \multicolumn{8}{|l|}{ IV. Psycodidae } \\
\hline 7. Psycoda sp. & 0 & 0,013 & 0,0029 & 0,0012 & $0-0,013$ & 0,0171 & 75 \\
\hline Total & 0,9877 & 0,9638 & 0,5062 & 1,1478 & & 3,6585 & \\
\hline Tot jenis & 6 & 7 & 7 & 6 & & & \\
\hline
\end{tabular}

Ind $=$ individu,$F K=$ Frekuensi kehadiran

Larva Diptera pada phytotelmata yang dominan adalah larva $A e$. albopictus yang ditunjukkan dari jumlah kepadatan larva Ae. albopictus sebesar 2,1103 individu /ml dengan (FK 100\%) diikuti larva $C x$. tritaeniorhynchus 0,554 individu/ ml (FK 100\%). Dari ke tujuh jenis larva yang ditemukan tingginya jumlah kepadatan larva Ae. albopictus ini mungkin diduga karena sesuainya tempat perindukan dengan ke- biasaan hidup nyamuk ini, disamping terpenuhi kebutuhan larva untuk untuk kelangsungan hidup larva. Ae.albopictus adalah nyamuk yang lebih menyukai hidup di luar rumah, daripada di dalam rumah. oleh karena itu nyamuk ini disebut juga nyamuk kebun. Tempat terbuka dengan berbagai jenis tanaman yang dapat menampung genangan air menjadi pilihan bagi nyamuk ini untuk mendapat tempat perin- 
dukan, selain itu Ae. albopictus adalah nyamuk yang lebih toleran terhadap kondisi lingkungan, dapat beradaptasi dengan tempat perindukan yang lebih beragam di alam seperti pada phytotelmata (Supartha, 2008; Yap,1975 dalam Khim, 2007). Phytotelmata seperti nanas, talas dan pisang merupakan habitat utama dari Ae. Simpsoni di Afrika (Pajot,1983). Keberadaan tempat perindukan nyamuk disekitar rumah juga akan memudahkan nyamuk dewasa untuk tetap mendapat asupan darah dari hospesnya yaitu manusia.

Untuk larva $C x$. tritaeniorhynchus kepadatannya juga cukup tinggi, hal ini mungkin disebabkan karena sesuainya tempat perindukan dengan kebiasaan nyamuk ini. Menurut Delfinado (1966) nyamuk Culex disebut juga nyamuk hutan karena menyukai hidup pada daerah yang banyak tumbuhannya seperti di hutan-hutan. Selain itu nyamuk ini sudah beradaptasi dengan tempat perindukan di alam seperti pada phytoyelmata. Hasil ini juga sesuai dengan laporan dari beberapa peneliti, bahwa ditemukan beberapa species nyamuk seperti Culex pipiens dan Culex nebulosus pada phytotelmata sebagai tempat perkembangbiakkan. (Service,1993; Lutwana dan Makwaya, 1994). Kepadatan terendah terdapat pada larva Psychoda sp. diduga rendahnya kepadatan dari larva ini kareana adanya persaingan dalam memperoleh makanan dengan jenis larva lainnya yang berakibat pada rendahnya jumlah kepadatan dari larva ini karena larva Psychoda sp.aktif memakan material yang membusuk di dalam air (Chu,1949).

Dari Gambar 2 terlihat ke tujuh larva Diptera terdistribusi pada ke empat jenis phytotelmata dengan nilai ragam Komponen Utama1. $(98,03 \%)$ dan nilai ragam Komponen Utama 2. $(1,55 \%)$ dan total keragaman sebesar $(99,58 \%)$, terdistribusi larva pada ke empat jenis phytotelmata, ini membuktikan bahwa phytotelmata tidak hanya sebagai tempat hidup, tetapi juga sebagai tempat berkembangbiak yang disukai oleh larva ini.

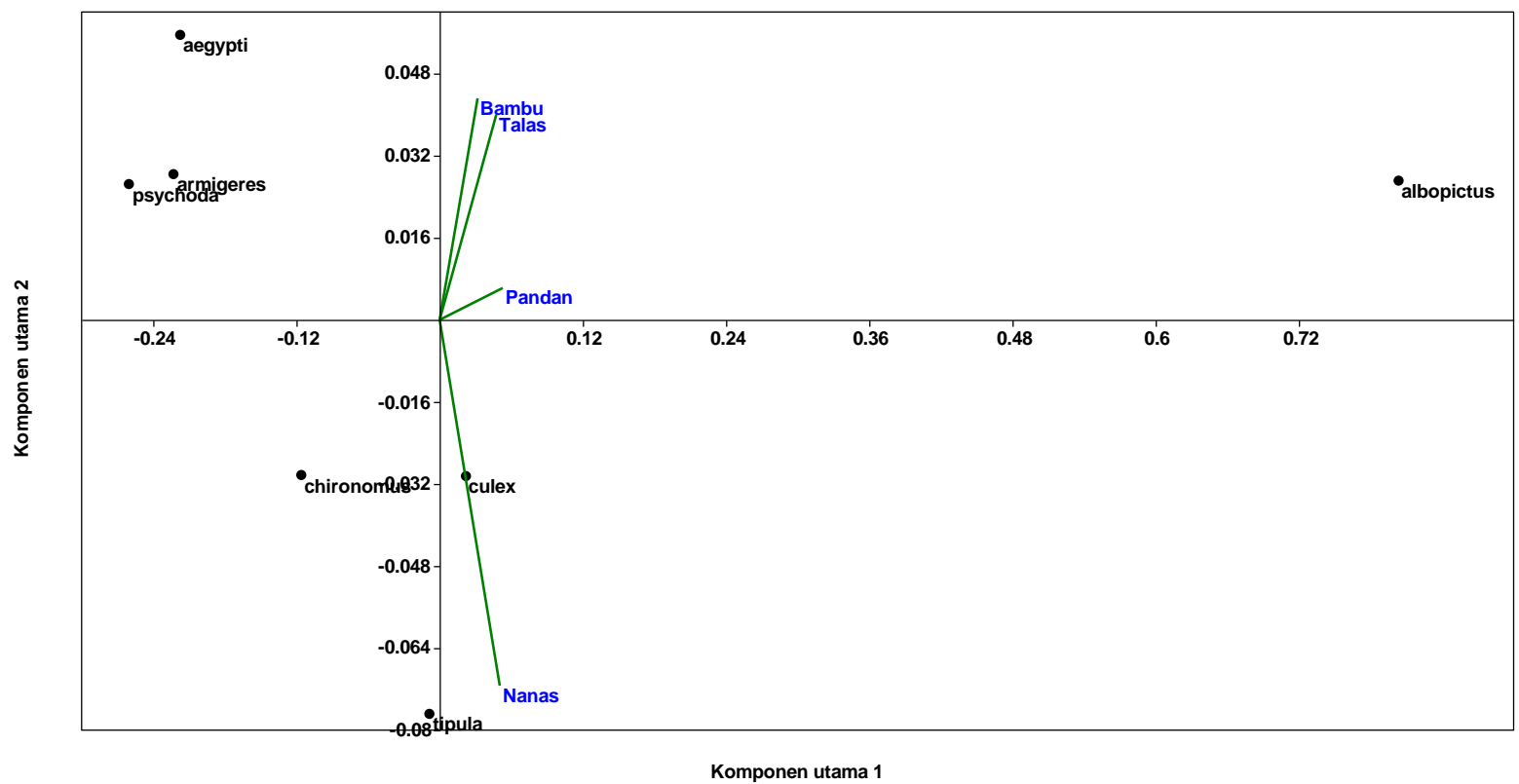

Gambar 2. Distribusi larva diptera pada phytotelmata

\section{KESIMPULAN}

Jenis larva Diptera yang ditemukan pada phytotelmata terdiri dari Ae. aegypti, Ae. albopictus, Cx. tritaeniorhynchus Ar. subalbatus, Chironomus sp., Tipula sp., Psychoda sp. Kepadatan larva tertinggi adalah $A$ e. albopictus sebesar 2,1103 individu /ml dengan (FK $100 \%$ ) diikuti larva $C x$. tritaeniorhynchus 0,554 individu/ ml (FK 100\%). dan sebagai larva penciri pada ke empat jenis phytotelmata adalah larva Ae. albopictus. Ke tujuh larva Diptera terdistribusi pada ke empat jenis phytotelmata dengan nilai ragam Komponen Utama1. (98,03\%) dan nilai ragam Komponen Utama 2. (1,55\%) dan total keragaman sebesar $(99,58 \%)$

\section{DAFTAR PUSTAKA}

Abbas,I., Dahelmi., L. M. Putri. 2003. Komposisi dan Struktur Komunitas Serangga Pada Phytotelmata di HPPB Universitas Andalas Padang. Makalah Disampaikan pada Se- 
minar dan Simposium Entomolog, Tanggal 5-7 Maret di Cipayung, Bogor, Jawa Barat

Adebote, D. A., D. S. Abolude., S. J. Oniye and O. S. Wayas. 2008. Studies on Some Physicochemical Factors Affeting the Breeding and Abundance of Mosquitoes (Diptera ;Culicidae) in Phytotelmata on Delonyx regia (Legumonosae: Caesalpiniaceae). Journal of Biological Science. 8 (8)1304 -1309.

Badan Meteorologi Klimatologi dan Geofisika (BMKG) Minangkabau dan Stasiun Klimatologi Sicincin Sumatera Barat. 2012. Monotoring curah hujan, tempratur dan kelembaban. bmkg@gmail.co; staklim scn@yahoo.com

Barrera, R., D. Fish., C. E. Machado -Alison. 1989. Ekological Patterns of Aquatic Insect Communities in two Heliamphora Pitcherplant species of the Venezuelan Hightlands, Ecotropicos. Vol 2(1): 31-44.

Chu, H. P. 1949. How to Know Imature Insect. Brow Company. Publisher. Dabucus Loa.

Delfinado, M. D. 1966. The Culicine Mosquito of the Filipine. Tribe Culicine (Diptera Culicine). The American Entomology Institute. USA.

Derraik, J. G. B. 2005. Mosquito Breeding in Phytotelmata in Native Forest in the Wellington Region, New Zealand. New Zealand Journal of Ecology. 29, 185-191.

Fish, D. 1983. Phytotelmata Flora dan Fauna. In: J. H. Frank \& L. P. Lounibos (Eds.) Phytotelmata Terestrial Plants as Host of Aquatic Insect Communicaties, Plexus, Medford. pp, 161-190.

Frank, J. H. 1983. Bromeliad Phytotelmata and their biota especially mosquito In: Frank J.H, .P Launibos, editors. Phytotelmata : terrestrial plants as host for aquatic insect communities. Plexus Publishing, Medford. pp, 101-128

Greeney, H. F. 2001. The Insects of Plant-Held Waters: A Review and Bibliography, Department of Entomology. Journal of Tropical Ecology. 17, 241-260.

Hammer. Q. 2011. Paleonthologycal Statistic (PAST) Version 2.10. National History Museum University of Oslo. http: folk.u10.no/ohammer/past.

Kim, P.C. 2007. Bionomics of Aedes aegypti and Aedes albopictus in Relation to Dengue Incidence on Penang Island the Application of Sequential Sampling in the Control of Dengue Vectors. Thesis Submitted in fulfilment of the requirements for the degree of Master Science. Universiti Sains Malaysia.

Kitching, R. L. 1971. An Ecology study of water filled tree- holes and their position in the woodland ecosystem. Journal of Animal Ecology. 40, 281-302.
Kitching, R..L. 2000. Food Web and container habitats: the natural history and ecology of phytotelmata . Cambrige University Press, Cambrige, UK.

Kitching, R.. L. 2001. Food web in phytotelmata. Botton up and top- down explanation for community structure. Annual Review Entomology, 46: 729-760.

Lutwana, J. J. and L. G. Mukwaya. 1994. Studies on some of the physical and biological factors affecting the abudance of the Aedes simpsoni (Diptera: Culicidae) complex- larvae and pupa in plant axils. Bulletin of Entomological Research. 81:255-263.

Maguire, B.1971. Phytotelmata: Biota and community structure determination in plant -held waters. Annual Review of Ecologi and Systematics. 2: 439-464.

Paradise, C. H. 2004. Relationship of water and leaf litter variability to insect inhibiting treeholes. Journa North American Benthologycal Society, 23(4) $793-805$

Phua Sai Gek,L., L.L. Song., Deng Lu., N.L.Ching. 2008. Some Common Mosquitoes and Nuisance insects in Singapura, Environmental Healt Institut (ehi), National Environment Agency

Phua Sai Gek,L., L.L. Song., Deng Lu., N.L.Ching. 2010. Some Common Mosquitoes and Nuisance insects in Singapura, Environmental Healt Institut (ehi), National Environment Agency

Pajot, F. X. 1983. Phytotelmata and Mosquito Vectors of Sylvatic Yellow Fever in Africa. In Phytotelmata Terestrial Plant as Host for Aquatic Insect Communities, Frank, J.H and Launios (Eds.). Flexus, Medford, New Yersey, pp: 79-99.

Rosa, E; S. Salmah; Dahelmi; Syamsuardi. 2012. Jenis dan tipe phytotelmata Sebnagai Tempat Perindukan Alami Nyamuk di Beberapa lokasi di Sumatera Barat, Prosiding Seminar Nasional Sains Matematika dan Aplikasinya III (SN-SMAIP 2012). Fakultas Matematika dan IImu Pengetahuan Alam, Universitas Lampung

Service, M. W. 1993. Mosquito (Culicidae). In: Medical Insect and Arachnids, Lane, R.P. and R.W. Crosskey (Eds.). Chapman and Hall, London. pp: 120-240.

Sunahara,T and M. Mogi.1997. Distribution of Larval Mosquitoes among Bamboo Stamp Pool which Vary in Persistency and Resource Input. Researches on Population Ecology. 39(2), pp173 - 179.

Supartha, I. W. 2008. Pengendalian Terpadu Vektor Virus Demam Berdarah Dengue, Aedes aegypti (Lin.) dan Aedes albopictus (Skuse) (Diptera: Culicidae). Pertemuan IImiah. Dies Natalis Universitas Udayana 3-7 September. Bali. 